\title{
Erratum to: The future of hybrid imaging-part 3: PET/MR, small-animal imaging and beyond
}

\author{
T. Beyer • L. S. Freundenberg • J. Czernin • \\ D. W. Townsend
}

Published online: 4 February 2012

(C) European Society of Radiology 2012

\section{Erratum to: Insights Imaging \\ DOI 10.1007/s13244-011-0085-4}

The authors of the article "The future of hybrid imaging — part 3: PET/MR, small animal imaging and beyond", published in Insights Imaging (2011) 2:235-246 would like to point out that Fig. 6 was composed from several sources for the purposes of illustration. During this process, the authors did not acknowledge the source of the small animal image in Fig. 6d appropriately. This image portion was taken from Goetz C, Breton E, Choquet P, Israel-Jost V, Constantinesco A (2008) SPECT-low field MRI system for small animal imaging. J Nucl Med 49:88-93. Goetz and colleagues were kind enough to point this out to the authors. We apologise for our neglect.

Henceforth, the correct figure caption to Fig. 6 should read: Fig. 6 Alternative combinations of imaging techniques in prototype designs and research testing: a) scintimmamography imaging [58], b) combined X-ray/ultrasound imaging [59], c) mammotomography [60] and d) SPECT/ MRI [42]. The small animal image in Fig. 6d was taken from Goetz C et al. J Nucl Med (2008) 49:88-93 and shows retrospectively fused $99 \mathrm{mTc}-\mathrm{SPECT}$ and T1w-MRI images of a mouse obtained with a combined SPECT/low field MRI small animal imaging prototype.

The online version of the original article can be found at http:// dx.doi.org/10.1007/s13244-011-0085-4.

\section{T. Beyer}

cmi-experts $\mathrm{GmbH}$,

Pestalozzistr 3,

8032 Zürich, Switzerland

T. Beyer $(\bowtie) \cdot$ L. S. Freundenberg

Department of Nuclear Medicine, University Hospital Essen,

Essen, Germany

e-mail: thomas.beyer@cmi-experts.com

L. S. Freundenberg

Department of Nuclear Medicine, ZRN,

Grevenbroich, Germany
J. Czernin

Department of Molecular and Medical Pharmacology,

David Geffen School of Medicine, UCLA,

Los Angeles, CA, USA

D. W. Townsend

Singapore Bioimaging Consortium,

11 Biopolis Way, 02-02 Helios,

Singapore 138667, Singapore 